\title{
Eğitim Bilişim Ağı Video Modüllerinin Fen Bilimleri Dersinde Kullanımına İliş kin Sekizinci Sınıf Öğrenci Görüşlerinin İncelenmesi
}

\section{Hasan BAKIRCI*, Kübra KILIÇ**}

Öz: Bu çalışmanın amacı, Eğitim Bilişim A ğı (EBA) video modüllerinin Fen Bilimleri dersinde kullanımına ilişkin sekizinci sınıf öğrencilerinin görüşlerini ortaya çıkarmaktır. Bu çalışma, nitel araştırma desenlerinden durum çalışması ile yürütülmüştür. Çalışmanın katılımcılarını 2020-2021 eğitim-öğretim y1lında Van'ın Tuşba ilçesinde bulunan bir ortaokulda sekizinci sınıfta öğrenim görmekte olan 10 öğrenci oluşturmaktadır. Çalışmanın verileri beş sorudan oluşan yarı yapılandırılmış görüşme formu ile toplanmıştır. Mülakatlar, ülkemizi etkisi altına alan Covid-19 salgını sebebiyle ZOOM programı üzerinden çevrim içi olarak gerçekleştirilmiştir. Çalışmada elde edilen veriler, betimsel ve içerik analiz ile çözümlenmiştir. Çalışmanın sonuçları incelendiğinde sekizinci sınıf öğrencileri EBA video modüllerinin faydalarını, birden fazla duyu organına hitap etme, konuları eğlenceli olarak öğrenmeyi sağlama, konuları pekiştirmeye yardımcı olma, konuları açık ve net olarak ele alma şeklinde belirtmişlerdir. Bunun aksine öğrenciler, konuların yüzeysel olarak ele alınmış olmasını, derse odaklanmayı zorlaştırdığını, videoların kısa ve zihinsel yorgunluğa sebep olduğunu, EBA video modüllerinin sınırlılıkları olarak ifade etmişlerdir. Ayrıca öğrenciler EBA video modüllerinin okulda kullanımı sırasında aksaklıklar yaşandığını, bu nedenle evde bireysel hızları doğrultusunda video modüllerinden faydalanmalarının daha verimli olacağını belirtmişlerdir. EBA video modüllerinin Fen Bilimleri dersi için öneminin daha iyi anlaşılması için, farklı öğretim kademesindeki öğrenciler ile yürütülmesi önerilmektedir.

Anahtar Kelimeler: Eğitim bilişim ağı, Video modülleri, Fen bilimleri dersi, Sekizinci sinıf öğrencileri.

\footnotetext{
* Doç. Dr. Van Yüzüncü Yıl Üniversitesi, Eğitim Fakültesi, Orcid ID: 0000-0002-7142-5271, Email: hasanbakirci09@gmail.com

** Yüksek Lisans Öğrencisi, Van Yüzüncü Yıl Üniversitesi Eğitim Bilimleri Enstitüsü, Orcid ID: 0000-0002-72132462, Email: kbraa.klc91@gmail.com

$\mathrm{Bu}$ araştırma için Van Yüzüncü Y 11 Üniversitesi Sosyal ve Beşeri Bilimleri Etik Kurulu Başkanlığında (17/02/2021) tarih ve 2021/02-18 sayısı) etik izin alınmıştır.
}

Gönderim:23.02.2021 Kabul:20.03.2021 Yayın:25.04.2021




\section{The Investigation of $8^{\text {th }}$ Grade Students Opinion towards The Use of Education Information Network Video Modules in Science Lessons}

Abstract: The aim of this study is to explore views of eighth grade students regarding the use of the Education Information Network (EIN) video modules in the Science course. The research was conducted with a case study from qualitative research designs. Participants of the study consist of 10 students who are studying in the eighth grade in the town of Tusba, Van, during 2020-2021 academic year. Semi-structured interviews consisting of five questions were used for data collection. The interviews were conducted online through the ZOOM program due to the Covid-19 pandemic. The data obtained in the study were analyzed by descriptive and content analysis. The results of the study show that eighth grade students found EIN video modules useful as it appeals to more than one sense, provides learning the topics with fun, helps to reinforce the topics, and deals with the subjects clearly. On the other hand, the students stated limitations of the EIN video modules such as; superficial tutoring of the subjects, difficulty of focusing on the class, the mental fatigue caused by videos. In addition, students stated that there were problems during the use of EIN video modules at school, so it would be more efficient to use video modules at home in line with their individual pace. In order to develop a better understanding of the importance of EIN video modules in Science course, more research can be carried out with students from different education levels.

Key Words: Education Information Network, Video modules, Science course, $8^{\text {th }}$ students.

\section{Giriş}

Hızla değişim ve gelişim gösteren teknoloji, yaşantımızın her alanında kendini göstermektedir. Teknolojideki bu gelişmeler insanların yaşam şeklini, devletlerin yönetim politikasını ve eğitim-öğretim süreci gibi ana unsurları etkilemektedir. Hiç kuşkusuz en çok bilgisayar ve internet teknolojisinin kullanımında artış gözlemlenmiş̧tir (Alaca ve Yılmaz, 2016). Türkiye İstatistik Kurumu’nun 2020 y1lında elde ettiği verilerde her on hanenin sekizinin internet erişim problemi yaşamadığı ve bu oranın Türkiye genelinde $\% 79$ olduğu belirlenmiştir (Türkiye İstatistik Kurumu [TÜİK], 2020). Sürekli gelişmekte olan dünyada, eğitim ve öğretimin çağın ihtiyaçlarına yönelik olması ülkeler için bir hedef kabul edilmiştir (Ateş, Çerçi ve Derman, 2015). Teknolojideki bu gelişmeler sayesinde eğitim de teknolojiye uyum sağlamış ve geliştirilen araçlar eğitimde kullanılmaya başlanmıştır (Alabay ve Taşdelen, 2017). Hayatı bu denli etkisine alan bilgisayar ve internet teknolojisi eğitim-öğretimde de yeni bir pencere açarak klasik öğrenme anlayışından farklı, fiziki mekândan bağımsız internet veri tabanlı 
öğrenme anlayışını beraberinde getirmiştir. İnternet veri tabanlı eğitim sisteminin bir diğer avantajı da yer ve zaman fark etmeksizin sınırsız bilgiye ulaşma imkânıdır (Brown, 2002; Gezer ve Durdu, 2020; Lee ve Baylor, 2006). Bu süreçte asıl amaç; bilgiyi ezberleyen ve bilgiyi hazır olarak elde eden bireyler yerine, olayları sorgulayıp özgün bakış açısıyla sorunların farkına vararak çözüm üretebilen, bilgiyi üretip kullanabilen, kendine güveni yüksek bireylerin yetiştirilmesidir (Yavuz ve Coşkun, 2008). Bu gelişmelerin ülkemizdeki yansımalarından biri Milli Eğitim Bakanlığı (MEB) tarafından 2010 yılında hayata geçirilen "Fırsatları Arttırma Teknolojiyi İyileştirme Hareketi (FATİH)” projesidir.

Türkiye'de başlatılan bu proje; "Vizyon 2023 içinde yer alan e-Dönüşüm Türkiye Projesi kapsaminda üretilen ve Türkiye'nin bilgi toplumu olma sürecindeki faaliyetlerini tanımlayan Bilgi Toplumu Strateji Belgesi, Kalkınma Planları, Eğitim Bakanlığı Stratejik Planı ve Bilişim Teknolojileri Politika raporunda yer alan amaçlar doğrultusunda hazırlanmış bir projedir"' şeklinde tanımlanmıştır (Akıncı, Kurtoğlu ve Seferoğlu, 2012, s.3). Bu proje ile birlikte öğrencilerin ihtiyaç duydukları bilgiye ulaşmalarının son derece hızlanıp kolaylaşacağı söylenebilir. FATİH projesi eğitimdeki fursat eşitsizliğini ortadan kaldırıp, teknolojik gelişmeyi sağlamak ve öğrencilerin farklı duyu organlarına hitap edecek teknolojiyi, öğrenme-öğretme sürecine etkin bir şekilde dâhil etmek için başlatılmıştır. Çünkü teknoloji, öğrenmenin daha etkili ve kaliteli olmasını sağlamaktadır (Namlu, 1999). FATİH projesinin eğitim ortamlarında var olduğunu gösteren en somut göstergeler etkileşimli (akıllı) tahta, bilgisayar, tablet ve EBA'dır (Özkan, 2019). FATİH projesi ile kurulan alt yapıyı daha işlevsel hale getirerek her ders için güvenilir ve doğru içerik oluşturmayı hedefleyen EBA 2012 yılında kurulmuştur. Milli Eğitim Bakanlığı EBA'nın kurulma amacını, hiçbir mekân gözetmeksizin ihtiyaç duyulan her yerde Bilişim İletişim Teknolojileri (BİT) araçlarının kullanılması ve teknolojinin eğitime entegrasyonu olarak tanımlamıştır (Aktay ve Keskin, 2016).

FATİH projesinin bir diğer önemli bileşeni EBA olarak tanımlanmıştır. EBA sınıf seviyelerini gözeterek, güvenilir ve taranmış içerikleri barındıran sosyal bir platformdur (Bektaş, 2019). Başta öğretmen ve öğrenciler olmak üzere tüm eğitim kademelerinde kullanılması için tasarlanan EBA;

- Çeşitli, özgün ve eğitici içerikler sunmak,

- Bilişim kültürünü arttırarak eğitime yön verilmesini sağlamak,

- İçerik ile ilgili ihtiyaçlarınıza yanıt vermek,

- Sosyal platform yapısıyla kesintisiz bilgi alışverişinde bulunmak,

- Zengin ve gittikçe büyüyen arşivi ile derslerin işlenmesine fayda sağlamak, 
- Öğrenilen bilgiyi canlı tutabilmek, yapılandırabilmek ve kalıcılığını sağlamak,

- Çeşitli öğrenme stillerine (sözel, görsel, sayısal, sosyal, bireysel, işitsel öğrenme) sahip öğrencileri de kapsamak,

- Tüm öğretmenleri ortak bir noktada buluşturarak eğitime katkı sağlamalarına ön ayak olmak,

- Teknolojiyi bir amaçtan ziyade, bir araç olarak kullanmak amacıyla oluşturulan sosyal bir eğitim platformudur (Milli Eğitim Bakanlığı [MEB], 2015) .

EBA öğrencilerin bireysel çabalarına göre öğrenme ortamı sunarak eğitimin okul dışında da sürdürülmesini sağlar. Ayrıca firsat eşitsizliği ve çeşitli imkânsızlıklardan dolayı örgün eğitim sürecinde bulunamayan öğrencilerin öğrenme süreçlerine devam edebilmeleri için iyi bir alternatif olarak düşünülmektedir. EBA'nın görevleri arasında hastalık, doğal afet veya kişisel sebeplerden ötürü eğitime katılamayan öğrencilerin ders ile ilgili ihtiyaçlarına cevap vermek yer almaktadır (Tüysüz ve Çümen, 2016).

EBA öğretmen ve öğrencilerin yararlanabileceği eğitim modüllerinin yanı sıra ses, görüntü, yazı, resim ve video gibi kaynakları da içermektedir (Aktay ve Keskin, 2016). Bununla birlikte öğretmen ve öğrencinin dosya paylaşacağı dijital bir alan sağlaması, öğrencilerin kendi aralarında iletişim kurabilmesi ve duyuru yapılabilmesi EBA sisteminin içeriğini zenginleştiren özelliklerdendir (Aktay ve Keskin 2016). EBA platformunda görsel video doküman içeriklerinin kaliteli olmasının ve farklı duyulara hitap etmesinin derslerde beklenen verimi arttıracağı belirlenmiştir (Ar, 2016; Kırıcı, Artun ve Bakırc1, 2018). EBA'nın ders tekrarı yapılarak konuyu pekiştirmede, okuduğunu anlamada, testleri çözebilme kabiliyetlerini arttırmada, akademik başarının ve bilginin yapılandırılmasında önemli bir rol oynadığ saptanmıştır (Açıkgöz, 2018). Bir başka çalışmada ise EBA'nın içerik modülleri ve sunduğu işlevselliğin üzerinde durulmuştur. Başka bir ifadeyle bu çalışmada EBA'nın tanıtımı yapılmıştır (Güvendi, 2014). Bu konuda Altın ve Kalelioğlu (2015), EBA kullanımı hakkında öğretmen ve öğrenci görüşlerini almıştır. Öğrenciler, EBA'da yayınlanan içeriklerin seviyelerine uygun olmadığını belirtmişlerdir. Bunun yanında öğretmenler ise FATİH projesinin eğitime yeterince katkı sağlamadığını, öğrencilere eğitim için dağıtılan tabletlerden yeteri kadar faydalanılmadığını ve amaca uygun kullanılmadığını ifade etmişlerdir. Öğretmenlerin EBA kullanım sıklığı ile ilgili çalışmalar mevcuttur. Sınıf öğretmenleri ile yapılan bir diğer çalışmada, öğretmenlerin EBA konusunda yeterli bilgi ve deneyimlere sahip olmadıkları ve EBA’yı sıklıkla kullanmadıkları görülmüştür. Bunun yanı sıra öğretmenler, EBA'yı verimli ve işlevsel bulmuşlardır (Kurtdede-Fidan, Erbasan ve Kolsuz, 2016). Bu 
konuda Tüysüz ve Çümen (2016), öğrencilerden EBA’yı eğitsel etkinlik, konu anlatımı, oyun, video modülleri ve testler açısından değerlendirmelerini istemiştir. Öğrenciler EBA’ya girişte sorun yaşama, EBA'daki sistem akışının yavaş işlediğini belirtme gibi nedenler ile eleştiride bulunmuşlardır. İlgi çekici oyunların, konu anlatımını pekiştirmek için etkinliklerin ve değerlendirme sorularının bulunduğu testlerin eklenmesi gerektiği sonucuna varılmıştır. Diğer taraftan Ateş, Çerci ve Derman (2015) çalışmalarında, EBA videolarının Türkçe dersine olan katkılarını incelemiştir. Elde edilen verilere göre, Türkçe videolarının süresinin yetersiz olduğu ve içerik yönünden zayıf olduğu sadece belirli konuların üzerinde durduğu belirlenmiştir.

EBA öğrencilerin ve öğretmenlerin faydalanması için tasarlanan bir web sitesidir (Atasoy ve Yiğitcan-Nayir, 2019). Bu yüzden EBA'nın artı ve eksi yönlerinin ortaya çıkarılması sistemdeki eksik noktaların tamamlanmasına ve geliştirilmesine olanak sağlayacaktır (Bahçeci ve Efe, 2018). EBA konusundaki eksikliklerin giderilmesi için bu eğitim sitesi ile devamlı etkileşimde bulunan öğretmen ve öğrencilerle çalışmalar sürdürebilmek önem arz etmektedir. Alanyazın incelendiğinde EBA video modüllerinin Fen Bilimleri dersi kapsamında kullanıldığı görülmektedir (Kırıc1, Artun ve Bakırc1, 2018). Kullanılan bu videoların öğrencilerin akademik becerilerini ve teknolojik ilgilerini arttırdığı yönünde çalışmalar olmakla beraber EBA’daki video modülleri ile ilgili öğrenci görüşlerine yönelik çalışmaların sınırlı olduğu belirlenmiştir. Diğer taraftan öğrencilerin video modülleri hakkındaki düşüncelerinin ortaya koyulmasının, bundan sonraki çalışmalara katkı sağlayacağı düşünülmektedir. Ayrıca ülkemizde bir buçuk yıldır süren salgın nedeniyle EBA'yı aktif bir şekilde kullanan sekizinci sınıf öğrencilerinin EBA hakkındaki eksiklerinin belirlenmesi ve bu konudaki eksiklerin giderilmesi açısından bu çalışmanın önemli olduğu düşünülmektedir. Bu bilgiler 1şı̆̆ında çalışmanın temel problemi, “EBA’da Fen Bilimleri dersi ile ilgili video modüllerinin kullanımına ilişkin sekizinci sınıf öğrencilerinin görüşleri nelerdir? Şeklinde belirlenmiştir.

\section{Yöntem}

\section{Araştırma Modeli}

$\mathrm{Bu}$ çalışma, nitel araştırma desenlerinden özel durum çalışması olarak tasarlanmıştır. $\mathrm{Bu}$ desenin seçilmesinde, belirli bir hedef için toplanan verilerin yorumlamalarının derinlemesine incelenmesi ve katılımcıların sınırlı sayıda olup EBA videoları gibi özel konuların ele alınması etkili olmuştur (Woodside, 2010; Yıldırım ve Şimşek, 2011). Bu çalışmada özel durum yöntemi kullanılmasındaki temel hedef, belirlenen problem durumu ile 
ilişkili sonuçlar elde etmek ve konuyu derinlemesine araştırarak konuyla ilgili ince detayları sebep sonuç ilişkilerini keşfederek incelemektir.

\section{Katılımcilar}

Çalışma, 2020-2021 eğitim-öğretim yılında Van'ın Tuşba ilçesinde bulunan bir devlet okulunun sekizinci sınıfında öğrenim görmekte olan 10 öğrenci ile yürütülmüştür. Katılımcılar uygun örnekleme yöntemi ile seçilmişlerdir. Çalışmaya katılan ortaokul öğrencilerinin 7'si kız, 3’ü erkek öğrenciden oluşmaktadır. Katılımcıları seçerken sekizinci sınıf seçme sebebi ise uygun örnekleme yöntemi kullanılmasından kaynaklanmaktadır. Uygun örnekleme yöntemi bir hedef doğrultusunda konu hakkında veri toplamayı kolaylaştıran küçük bir kümenin örneklem olarak değerlendirilmesidir (McMillan ve Schumacher, 2014).

\section{Verilerin Toplanması}

Verilerin toplanmasında yarı yapılandırılmış görüşme formu kullanılmıştır. $\mathrm{Bu}$ çalışmada yarı yapılandırılmış görüşme formu kullanılmasındaki amaç katılımcıların kendini rahatça ifade edebilmesi ve orijinal ifadeler ile derinlemesine bilgi edinilmesine olanak sağlanmasıdır (Yıldırım ve Şimşek, 2011). Yarı yapılandırılmış görüşme formu ilk planlanan hali ile dokuz adet soru içermektedir. Fen eğitiminde doktora yapmış iki öğretim elemanı ve üç yüksek lisans öğrencisinin görüşleri alındıktan sonra formdaki soru sayısı beşe indirilmiştir. Görüşleri alınan iki öğretim elemanının nitel konularda makaleleri bulunmaktadır. Görüşüne başvurulan yüksek lisans öğrencileri ise Fen Bilimleri öğretmeni olup fen eğitimi alanında eğitim görmektedirler. Görüşme formundan çıkarılan sorular, "EBA videolarında hoşuna giden yönler nelerdir?”, “Diğer Fen Bilimleri konularının nasıl anlatılmasını istersin?” ,"EBA videolar kullanılmayan fen bilimleri dersinin avantajlart nelerdir?"” ve "EBA videolart kullanılmadan işlenen fen bilimleri dersinde sizi zorlayan değişkenler nelerdir?', şeklindedir. Soruların çıkarılma sebepleri öğrenci seviyesine uygun olmaması, çalışmanın amacına hizmet etmemesi ve soru içeriklerinin bezer olmasından kaynaklanmaktadır. Yarı yapılandırılmış görüşme formunda yer alan sorular EK-1'de verilmiştir. Görüşmeler ülkemizi etkisi altına alan Covid-19 salgını sebebiyle ZOOM programı üzerinden çevrim içi olarak gerçekleştirilmiştir. Görüşmeler çalışmaya katılan öğrencilerden müsaade alınarak ses kayıt cihazı ile kayıt edilmiştir. Her bir görüşme tahminen 20-25 dakika sürmüştür. Daha sonra bu ses kayıtları metin haline getirilmiştir. 


\section{Çalışmanın Geçerliliği ve Güvenirliği}

Nitel verilerin analizleri çalışmanın problem durumuna uygun olarak hazırlanan mülakat sorularına verilen yanıtlar doğrultusunda incelendikten sonra tema ve kodlar oluşturarak yapılmıştır. Merriam'a (2013) göre nitel bir çalışmada uzman görüşü almak iç geçerliliği sağlamak için kullanılan yöntemlerden biridir. Bu çalışmada da fen eğitimi alanında nitel çalışmaları bulunan iki öğretim üyesi elde edilen bulguları okuyup temalar ile tutarlılığını karşılaştırmıştır. Güvenirliği arttırmak için, çalışma sorularının sade anlaşılır şekilde olup çok boyutlu olmaması ve katılımcıyı yönlendirmeden düşüncelerin rahatça ifade edilebileceği şekilde olması gibi ana ilkeler göz önünde bulundurulmuştur. Son olarak ham veriler/işlenmemiş veriler, bulgular, yorum ve öneriler kayıt altına alınarak doğrulanabilirlik kriterinin sağlanması amaçlanmıştır.

\section{Verilerin analizi}

Verilerin analizinde betimsel ve içerik analizi kullanılmıştır. Betimsel ve içerik analizi kullanılmasındaki amaç, toplanan verilerin okuyucuların anlayabileceği biçimde sadeleştirilerek ve yorumlanarak sunulmasıdır (Yıldırım ve Şimşek, 2011). Görüşmeye katılan öğrenciler $\ddot{O}_{1}, \ddot{O}_{2}$, Ö $3{ }_{3} .$. Ö$_{10}$ şeklinde kodlanmıştır. Kodlamaya yapılırken öğrencilerin kişisel bilgileri gizli tutulmuştur. Katılımcıların görüşme sorularına verdikleri yanıtlar hiçbir değişiklik yapılmadan eksiksiz yazıya dökülmüştür. Çalışmanın son hali iki araştırmacı tarafından farklı zamanlarda incelenmiştir. $\mathrm{Bu}$ incelemelerden sonra her bir araştırmacı tema ve kodlar oluşturmuştur. Daha sonra araştırmacılar bir araya gelerek yapmış oldukları analizleri değerlendirmişlerdir. Bu değerlendirmede görüş birliğine varamadıkları tema ve kodlar ile ilgili tartışmalar yaparak anlaşmaya varmışlardır (Denzin ve Lincoln, 1994). Böylelikle araştırmacılar görüş birliğine vararak çalışmaya son halini vermişlerdir. Araştırmacılar tema ve kodların tutarlılığını belirlemek için Miles ve Huberman (1994) tarafindan kodlayıcılar arası güvenirlik formülünden faydalanmışlardır. Bu formüle göre üç araştırmacının yapmış oldukları veri analizinin uyuşma oranı \%83 olarak hesaplanmıştır. Bu oran, verilere ilişkin kodlamaların güvenilir bir yapıya sahip olduğunu göstermektedir (Miles ve Huberman, 1994).

\section{Etik Kurul Kararı}

Van Yüzüncü Yıl Üniversitesi Sosyal ve Beşeri Bilimleri Yayın Etik Kurulu'nun, 17/02/2021 tarih ve 2021/02-18 sayılı kararı gereği çalışma açısından Sosyal ve Beşeri Etik Kuralları ve İlkeleri çerçevesinde herhangi bir sakınca olmadığına karar verilmiştir. 


\section{Bulgular}

Bu çalışmanın katılımcılarının görüşme formunda yer alan sorulara vermiş oldukları cevaplar, soru bazında incelenerek okuyuculara aktarılmıştır. Katılımcıların görüşme formundaki birinci soruya verdikleri cevaplardan hareketle oluşturulan tema ve kodlar Tablo 1’de verilmiştir.

Tablo 1. Katılımcıların Fen Bilimleri Dersinde EBA Video Kullanmalarının Avantajları Nelerdir? Sorusuna Verdikleri Cevaplardan Elde Edilen Tema ve Kodlar

\begin{tabular}{|c|c|c|c|c|c|c|c|c|c|c|c|}
\hline Tema & Kodlar & $\ddot{O}_{1}$ & $\ddot{O}_{2}$ & $\ddot{\mathbf{O}}_{3}$ & $\ddot{\mathbf{O}}_{4}$ & $\ddot{\mathbf{O}}_{5}$ & $\ddot{\mathbf{O}}_{6}$ & $\ddot{\mathbf{O}}_{7}$ & $\ddot{O}_{8}$ & Ö$_{9}$ & $\ddot{O}_{10}$ \\
\hline \multirow{9}{*}{ 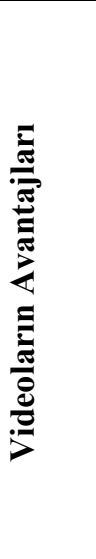 } & Daha fazla duyu organına hitap etme & $*$ & $*$ & $*$ & $*$ & & $*$ & $*$ & & $*$ & $*$ \\
\hline & Konuları daha açık ve net işleme & $*$ & & $*$ & & $*$ & $*$ & $*$ & $*$ & $*$ & \\
\hline & Konuları öğrenmeme yardımcı olma & $*$ & $*$ & & $*$ & & $*$ & $*$ & $*$ & $*$ & \\
\hline & İstenilen zamanda ders dinleme imkânı & $*$ & & $*$ & & $*$ & & & $*$ & $*$ & $*$ \\
\hline & Anlamadığım konuları tekrar etme & $*$ & & $*$ & $*$ & & & $*$ & & $*$ & \\
\hline & Konuları eğlenceli şekilde öğrenme & & & $*$ & & $*$ & & $*$ & & $*$ & \\
\hline & Soru çözmeme yardımcı olma & $*$ & & & * & & $*$ & & $*$ & & \\
\hline & Konuları pekiştirmeme yardımcı olma & $*$ & & & & $*$ & & & $*$ & & \\
\hline & Başarılı olmamı sağlama & $*$ & & & & $*$ & & $*$ & & & \\
\hline
\end{tabular}

Tablo 1 incelendiğinde EBA video modüllerinin avantajları hakkında öğrencilerin farklı şekillerde görüşleri olduğu görülmektedir. Söz konusu video modüllerinin avantajları hakkında Ö${ }_{3}$; “Görsellik daha iyi, konular daha açık ve net işleniyor, anlamadı̆̆ım konuları tekrar edebiliyorum." şeklinde görüş bildirerek Fen Bilimleri dersinde EBA video modülleri kullanımının konuyu kavramada etkili olduğuna ve videoların görsellikle zenginleştirildiğine vurgu yapmıştır. Bunun yanı sıra Ö aktiviteler sayesinde hem konu pekişiyor hem de konu işlerken sıkılmıyoruz. Dolayısıyla Fen Bilimleri dersinde daha başarılı olmamıza yardımcı oluyor. ” şeklinde görüşlerini dile getirerek EBA video modüllerinin akademik başarıyı arttırmak için etkili içerikler barındırdığını ifade etmiştir.

Katılımcıların görüşme formunun ikinci sorusuna verdikleri cevaplardan elde edilen tema ve kodlar Tablo 2'de verilmiştir. 
YYÜ Eğitim Fakültesi Dergisi (YYU Journal of Education Faculty), 2021; 18(1)685-705,http://efdergi.yyu.edu.tr,

Tablo 2. Katılımcıların EBA Videoları Kullanılmadan Işslenen Fen Bilimleri Dersinde Eksik Gördüğ̈̈nüz Noktalar Nelerdir? Sorusuna Verdikleri Cevaplardan Oluşturulan Tema ve Kodlar

\begin{tabular}{|c|c|c|c|c|c|c|c|c|c|c|c|}
\hline Tema & Kodlar & $\ddot{O}_{1}$ & $\ddot{\mathrm{O}}_{2}$ & $\ddot{\mathbf{O}}_{3}$ & $\ddot{\mathrm{O}}_{4}$ & $\ddot{O}_{5}$ & Ö$_{6}$ & $\ddot{\mathbf{O}}_{7}$ & $\ddot{O}_{8}$ & $\ddot{O ̈}_{9}$ & $\ddot{O}_{10}$ \\
\hline \multirow{7}{*}{ 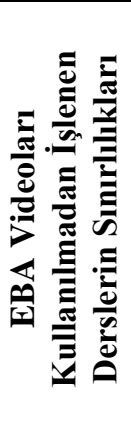 } & Görselliğin olmaması & $*$ & $*$ & $*$ & $*$ & & $*$ & $*$ & $*$ & $*$ & $*$ \\
\hline & Deney yapma imkânımızın olmaması & $*$ & $*$ & $*$ & & $*$ & $*$ & & $*$ & $*$ & \\
\hline & $\begin{array}{l}\text { Yeterli soru çözememe ve zaman } \\
\text { kaybının olması }\end{array}$ & $*$ & $*$ & & $*$ & & * & $*$ & & $*$ & \\
\hline & Ezbere dayalı dersin işlenmesi & $*$ & & $*$ & & $*$ & & $*$ & & & $*$ \\
\hline & Konu ve soru ağırlıklı dersin işlenmesi & & $*$ & & & $*$ & & $*$ & & $*$ & \\
\hline & Konuyu pekiştirmede yetersiz olması & $*$ & & $*$ & & & & & $*$ & & $*$ \\
\hline & Etkili öğrenememe & $*$ & & & & $*$ & & & & $*$ & \\
\hline
\end{tabular}

Tablo 2, katılımcıların "EBA videoları kullanılmadan işlenen derslerin sinırlılıkları" teması farklı görüşlere sahip olduğunu göstermektedir. Bu konuda Ö6 katılımcısının; “Konuları eğer tam anlayamazsam soru çözemiyorum ve zaman kaybı yaşıyorum. Videolar olmadığ zaman genellikle görselliğin fazla olmadı̆̆ şekilde ders isliyoruz bu yüzden bazı konuları kavrayamıyorum." ş̧eklindeki görüşü ile videoların Fen Bilimleri dersinde görsel yönden öğrencilerin anlamlı öğrenmelerine katkıda bulunduğu belirtilmiştir. Ayrıca Ö 3 katılımcısı; "Okulda dersi çok iyi anllyorum ama bazen deney yapamıyoruz. Videolarda öğretmenimiz deney ortamlarını gösterince daha iyi anlıyorum.” şeklinde görüşü ile EBA videolarının deneysel ortam oluşturarak öğrenmenin daha somut hale getirilmesine olanak sağladığ1 vurgulanmıştır.

Katılımcıların mülakatın üçüncü sorusuna verdikleri cevaplardan elde edilen tema ve kodlar Tablo 3' de verilmiştir.

Tablo 3. Katılımcıların EBA Videoları Kullanılarak Işslenen Fen Bilimleri Dersinde Zorlandı̆̆ınız Noktalar Nelerdir? Sorusuna Verdikleri Cevaplardan Oluşturulan Tema ve Kodlar

\begin{tabular}{|c|c|c|c|c|c|c|c|c|c|c|c|}
\hline Tema & Kodlar & Ö$_{1}$ & $\ddot{\mathbf{O}}_{2}$ & $\ddot{\mathbf{O}}_{3}$ & Ö$_{4}$ & Ö$_{5}$ & Ö$_{6}$ & Ö$_{7}$ & Ö$_{8}$ & Ö$_{9}$ & Ö$_{10}$ \\
\hline \multirow{9}{*}{ 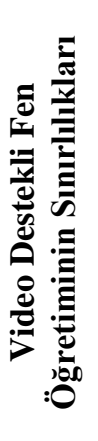 } & Derste dikkatin dağılması & $*$ & & $*$ & & $*$ & $*$ & * & $*$ & * & $*$ \\
\hline & Konuların yüzeysel anlatılması & $*$ & $*$ & & & $*$ & & $*$ & $*$ & & $*$ \\
\hline & Videoların kısa olması & $*$ & & $*$ & & & $*$ & $*$ & & $*$ & \\
\hline & Eksik öğrenmeyi sağlaması & & $*$ & & & $*$ & & $*$ & & & $*$ \\
\hline & $\begin{array}{l}\text { Videolarda kullanılan ses tonundan } \\
\text { rahatsızlık vermesi }\end{array}$ & $*$ & & & $*$ & & & $*$ & & * & \\
\hline & Videoların sürekli donması & $*$ & & $*$ & & $*$ & & & & & $*$ \\
\hline & Derse odaklanmamı zorlaştırması & & & $*$ & & & & $*$ & & $*$ & \\
\hline & Zihinsel yorgunluk sağlaması & $*$ & & $*$ & & & $*$ & & & & \\
\hline & Öğrenme ortamının sanal olması & & $*$ & & & $*$ & & & & & \\
\hline
\end{tabular}


Tablo 3 katılımcıların “Video destekli Fen Öğretiminin Sınırlılıkları” teması altında, farklı görüşlere sahip olduğunu göstermektedir. Bu konuda Ö 5 katılımcıs1; “EBA videolarını izlediğimde yeterli olduğunu düşünüyorum, fakat soru çözdüğümde bir sürü ayrıntıya videolarda yer verilmediğini fark ediyorum.” şeklinde görüş beyan ederek EBA videolarında yüzeysel bir anlatım olduğunu vurgulamıştır. Ayrıca Ö ${ }_{1}$ katılımcısı; “Videoların can sıkıcı ses tonuyla anlatılması sıkılmamıza sebep oluyor. Videolar biraz daha uzun olup, eğlenceli hale getirilmeli.” şeklinde görüş beyan etmiştir. Aynı soruya Ö 3 katılımcısı; “Derse odaklanmada sorun yaşıyorum. Videoları izlerken zihinsel olarak yorgun düşüyorum.’’ şeklinde görüş beyan etmişstir.

Katılımcıların görüşme formunun dördüncü sorusuna verdikleri cevaplardan elde edilen tema ve kodlar Tablo 4’te verilmiştir.

Tablo 4. Katılımcıların EBA Video İçeriklerinin Fen Bilimleri Dersi Iç̧in Yeterli Olup Olmadĭ̆ı Konusundaki Düşünceleriniz Nelerdir? Sorusuna Verdikleri Cevaplardan Oluşturulan Tema ve Kodlar

\begin{tabular}{|c|c|c|c|c|c|c|c|c|c|c|c|}
\hline Tema & Kodlar & $\ddot{O}_{1}$ & $\ddot{\mathbf{O}}_{2}$ & $\ddot{\mathbf{O}}_{3}$ & $\ddot{\mathbf{O}}_{4}$ & $\ddot{\mathbf{O}}_{5}$ & Ö$_{6}$ & $\ddot{\mathbf{O}}_{7}$ & $\ddot{O}_{8}$ & Ö$_{9}$ & $\ddot{\mathbf{O}}_{10}$ \\
\hline \multirow{7}{*}{ 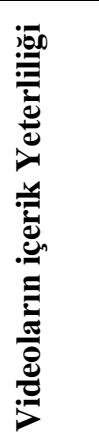 } & Yüzeysel ve kısa olması & $*$ & $*$ & $*$ & * & $*$ & $*$ & $*$ & $*$ & * & $*$ \\
\hline & Soruların çözümüne dönüt alamamak & $*$ & & & $*$ & $*$ & * & * & $*$ & & $*$ \\
\hline & İçeriklerde eksiklik olması & $*$ & & $*$ & & & $*$ & $*$ & & $*$ & \\
\hline & Soru çözme imkânı olmaması & & $*$ & & & * & & & & & \\
\hline & $\begin{array}{l}\text { Videolarda anlatılanlar birbiriyle } \\
\text { bağımsız olması }\end{array}$ & * & & $*$ & & & $*$ & & $*$ & & \\
\hline & Videoları takip etmekte zorlanma & & & & & & & & $*$ & & \\
\hline & Videodaki ses tonunun uykumu getirmesi & & $*$ & & & & & & & & $*$ \\
\hline
\end{tabular}

Tablo 4 katılımcıların “Videoların Iç̧erik Yeterliliği” teması altında, farklı görüşlere sahip olduğunu göstermektedir. Katılımcılar bu konuda görüşlerini; yüzeysel ve kısa olma, takip etmede zorluk, soru çözme imkânı olmaması, soruların çözümüne dönüt alamamak ve içeriklerde eksiklik olması kodlarıyla dile getirmişlerdir. Bu konuyla ilgili Ö 7 katılımcısı; “Bence yeterli değil, çok yüzeysel anlatım var, daha detaylı anlatılsa daha iyi anlarız.” şeklinde görüş beyan etmiştir. Aynı soruya ilişkin $\mathrm{Ö}_{6}$ katılımcısı; “Video içeriklerinin yeterli olduğunu düşünmüyorum. Çok kısa iki dakikalık videolar dikkatimi dağıtıyor. Hepsi bir videoda olup bir de anlatım yapan kişiyi görseydik daha etkili olurdu.” ş̧eklinde görüş sunmuştur. Ö10 katılımcısı ise; “Íçerikler çok yüzeysel videoları seslendiren kişinin ses tonu uykumu getiriyor.” şeklinde görüş ifade etmiştir.

Katılımcıların görüşme formunun beşinci sorusuna verdikleri cevaplardan oluşturulan tema ve kodlar Tablo 5’de verilmiştir. 
Tablo 5. Katılımcıların EBA Videolarında En Çok Dikkatinizi Çeken, Güdüleyen Yönler Nelerdir? Sorusuna Vermiș Oldukları Cevaplardan Oluşturulan Tema ve Kodlar

\begin{tabular}{|c|c|c|c|c|c|c|c|c|c|c|c|}
\hline Tema & Kodlar & $\ddot{O}_{1}$ & $\ddot{\mathbf{O}}_{2}$ & $\ddot{\mathbf{O}}_{3}$ & $\ddot{\mathbf{O}}_{4}$ & $\ddot{\mathbf{O}}_{5}$ & Ö$_{6}$ & $\ddot{\mathbf{O}}_{7}$ & $\ddot{O}_{8}$ & Ö$_{9}$ & $\ddot{\mathbf{O}}_{10}$ \\
\hline \multirow{9}{*}{ 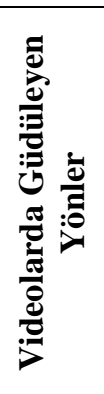 } & Videolardaki zengin görselliğin olmas1 & $*$ & $*$ & $*$ & $*$ & $*$ & & $*$ & $*$ & $*$ & $*$ \\
\hline & Eğlenceli olması & & & $*$ & $*$ & & $*$ & $*$ & & $*$ & $*$ \\
\hline & Etkinliklerin var olması & $*$ & & & $*$ & $*$ & $*$ & $*$ & & & \\
\hline & Videoların k1sa olması & $*$ & $*$ & & & $*$ & & & $*$ & & $*$ \\
\hline & Günlük hayatla ilişkili olması & & $*$ & & $*$ & & $*$ & & & $*$ & \\
\hline & Merak uyandırması & $*$ & & & $*$ & & & & $*$ & & \\
\hline & Derse olan motivasyonu arttırma & $*$ & & $*$ & & & $*$ & & & $*$ & \\
\hline & Daha fazla soru tipi görme & & $*$ & & & $*$ & & $*$ & & & $*$ \\
\hline & Soru çözme isteğini arttırma & $*$ & & & & $*$ & & & & $*$ & \\
\hline
\end{tabular}

Tablo 5 katılımcıların “Videolarda Güdüleyen Yönler” teması altında, farklı görüşlere sahip olduğunu göstermektedir. Katılımcılardan $\mathrm{Ö}_{4} ;$ EBA videolarında dikkatimi çeken kısım etkinliklerin çok olması ve görselliktir.” şeklinde görüş beyan etmiştir. Aynı soruya $\ddot{O}_{5}$ ve $\ddot{O}_{6}$ katılımcıları; "Etkinliklerin var olması” şeklinde görüş bildirmişlerdir. Aynı şekilde $\mathrm{Ö}_{3}$ ve $\mathrm{O}_{4}$ katılımcıları; "Videoların eğlenceli olması" şeklinde görüş dile getirmişlerdir. Konuyla ilgili $\mathrm{O}_{2}$ ve Ö 10 rumuzlu öğrenciler; Videoların kisa olması hoşuma gidiyor.” şeklinde görüş beyan etmiştir.

\section{Sonuç, Tartışma ve Öneriler}

Öğrenciler, EBA video destekli fen öğretiminin avantajlarını birden fazla duyu organına hitap etme, konuların anlaşılmasını kolaylaştırma, istenilen zamanda öğrenme imkânı sunma ve konuları tekrar etme şeklinde ifade etmişlerdir. Öğrencilerin bu şekilde görüş beyan etmelerinde; videolu derslerin görsel ve işitsel anlamda katkı sağlamış olmasının etkili olduğu düşünülmektedir. Teknoloji destekli fen öğretimine yönelik çalışmalar incelendiğinde, video, bilgisayar ve benzetim gibi teknolojik araçların öğrencilerin fen derslerindeki akademik başarısı ve bilimsel düşünme becerileri üzerinde etkili olduğu tespit edilmiştir (Akdeniz, Öztürk ve Bakırcı, 2017). Benzer şekilde Açıkgöz (2018)'ün yapmış olduğu çalışmada EBA destekli matematik öğretiminin, konuları pekiştirdiği, konuları tekrar etme imkânı sağladığı, test çözme becerilerini geliştirdiği ve akademik başarıyı artırdığı sonucuna ulaşmıştır. Aynı şekilde Tüysüz ve Çümen (2016) ortaokul öğrencilerinin görüşlerini aldıkları çalışmalarında EBA'nın akademik başarıyı arttırdığı, test çözme ve konu tekrarı yapma imkânı sağladığı yönünde bulgulara ulaşmışlardır. Bu çalışmada elde edilen sonuçlar değerlendirildiğinde, alan yazında yapılan diğer çalışmaların sonuçları ile benzerlik gösterdiği görülmektedir (Alabay, 2015; Atasoy ve Yiğitcan-Nayir, 2019; Gezer ve Durdu, 202). Öğrenciler EBA video destekli fen öğretiminin, konuların öğrenilmesini eğlenceli hale getirdiğini ifade etmişlerdir. Bu bulgunun ortaya çıkma nedenlerinden biri, öğrencilerin daha çok ders kitabı ile ders yapma durumunu 
farklı olarak algılamış olmaları ile açıklanabilir. Bu bulgunun ortaya çıkma nedenlerinden diğeri ise öğrencilerin videoları oyun temelli olarak düşünmeleri ve günlük hayatta zamanlarının belirli bir kısmını tablet, telefon ve bilgisayar ile geçirmeleri ile açıklanabilir.

Öğrenciler, EBA videoları kullanılmadan işlenen Fen Bilimleri dersinin pek çok sınırlılığına dikkat çekmişlerdir. Öğrenciler bu sınırlılıklardan bazılarını, görsel yönden eksikliklerin olması, deney yapma imkânının yetersiz olması, konu anlatımının ezber ağırlıklı ilerlemesi şeklinde sıralamıştır. Okullardaki araç gereç eksikliği, öğretim programının yoğunluğu, maliyetsel sıkıntıların olması öğrencilerin bu şekilde görüş belirtmelerindeki nedenler olarak değerlendirilebilir. EBA ile ilgili yapılan çalışmalar incelendiğinde; öğretmenlerin materyalleri etkin bir şekilde kullanabilmesi için fiziksel alt yapının tamamlanması gerekmektedir (Saklan ve Cezmi, 2018). Benzer şekilde Alabay (2015), EBA platformunun öğretmenler tarafından aktif kullanılmama sebebinin okullardaki alt yap1 eksikliği olduğunu belirtmiştir. Öğrencilerin deney yapma imkânının yetersiz olduğu şeklindeki görüşlerinde ise Fen Bilimleri dersinde deney sırasında karşılaşılacak tehlikelerin, sınıf ortamının kalabalık olmasının, materyal imkânının ve fiziksel ortamların uygun olmamasının etkili olduğu düşünülmektedir. Deneylerin yapılmadığı, olumsuz koşulların olduğu sınıflarda teknoloji daha çok önem kazanmaktadır. Bu bağlamda yapılan çalışmalara bakıldığında Efe, Oral, Efe ve Sünkür (2011) benzetim kullanımının öğrencilere bilişsel beceri kazandırma noktasında daha etkili olduğunu belirtmişlerdir. Teknolojinin işlevsel olarak kullanıldığı derslerde öğrenciler daha ilgili ve özverili olmaktadır (Saklan ve Cezmi, 2018). Bu noktada EBA videolarından Fen Bilimleri dersinde yararlanmanın dersi somut hale getirip, görsel zenginlik sağlayacağı ve imkân yetersizliklerinden dolayı deney yapma imkânı olmayan konularda benzetim öğretimi ile daha verimli ders işleme imkânı sunacağı düşünülmektedir.

EBA videoları kullanılarak işlenen Fen Bilimleri dersinin zorlukları hakkındaki öğrenci görüşlerinden bazıları; dikkat dağınıklığı, derse odaklanmada zorlanma, konuların yüzeysel ve kısa anlatılması olduğu belirlenmiştir. Bu bulgunun ortaya çıkmasında; öğrencilerin EBA kullanılan derste sürekli tahtaya bağlı kalıp pasifleşmelerinin, videoların kısa olması nedeni ile derste kopukluk yaşamalarının ve dikkat dağınıklığının etkili olduğu düşünülmektedir. Özbay (2008)'ın yapmış olduğu çalışmada, öğrencinin pasif olarak yer aldığı öğrenme ortamlarında etkili öğrenmenin gerçekleşmeyeceğini belirtmiştir. Benzer çalışmalara bakıldığında Ateş, Çerci ve Derman (2015) EBA'da bulunan videoları taradığında, videoların süre bakımından yetersiz olduğu, videoların sınıflara göre eşit dağılmadığı ve bazı video içeriklerinin öğrenci sınıf seviyelerine uygun olmadığı sonucuna ulaşmıştır. Öğrencilerin EBA videoları kullanılarak 
işlenen derste videodaki ses tonundan rahatsız olduklarını, hatta bu seslerin kendilerinin uykularını getirdiğini ifade etmeleri bu çalışmada dikkat çeken bir diğer sonuç olarak belirlenmiştir. Bu bulgunun ortaya çıkmasında öğretmenin jest ve mimiklerini görmeden sadece duydukları ses ile iletişim kuran öğrencilerin belli bir süre sonra aynı ses tonundan sıkılarak derse yönelik dikkat ve ilgilerinin azalmasının etkili olduğu düşünülmektedir.

Video içeriklerinin Fen Bilimleri dersi için yeterli olup olmadığı görüşme formunun üçüncü sorusu ile belirlenmiştir. Öğrenciler bu konuda video destekli fen öğretiminin yüzeysel ve süre bakımından yetersiz olduğunu, soruların çözümüne yönelik dönüt olmadığını ve içeriklerin konuyu tam olarak yansıtmadığını dile getirmişlerdir. Öğrencilerin bu şekilde görüşler beyan etmelerinde, videoların içerik dağılımının eşit olmamasının ve süre bakımından değişiklik göstermesinin etkili olduğu düşünülmektedir. Çakmak ve Taşkıran (2017) tarafından yapılan çalışmada, EBA'da bulunan Fen Bilimleri dersine ait içeriklerin zenginleştirilip geliştirilmesi gerektiği ve Sosyal Bilgiler dersi için EBA’daki içeriğin yetersiz olduğu sonucuna ulaşılmıştır. Bu konuda Alaybay (2015) öğrenci ve öğretmenler ile bir çalışma yürütmüştür. Bu çalışmada öğretmen ve öğrenciler EBA ders içeriklerinin yetersiz olduğu ve EBA'nın öğretim materyalleri açısından zenginleştirilmesi gerektiğini belirtmişlerdir. Dolayısıyla bu çalışmada elde edilen sonuçlar, önceden yapılmış çalışmaların sonuçları ile uyumlu olup, EBA'daki video içeriklerinin zenginleştirilmesi gerekliliğini ortaya koymaktadır.

Öğrenciler genel olarak EBA videolarının kendilerini güdüleyen yönlerini; görsel yönden zengin olması, eğlenceli olması, videoların kısa olması, derse karşı motivasyonlarını ve soru çözme isteklerini arttırması şeklinde dile getirmişlerdir. Öğrencilerin EBA video kullanımında sıklıkla vurguladıkları nokta videoların görsel açıdan zengin olduğudur. Katılımcıların bu düşüncelerinde, Fen Bilimleri dersinin yoğun görsellikler içeren ve uygulamalı bir ders olmasının etkili olabileceği düşünülmektedir. Çünkü görselliğin fazla olması dersin akılda kalıcılığını arttırmada etkilidir. Öğrenci görüşlerinin değerlendirildiği bir başka çalışmada Kana ve Saygılı (2016) öğrencilerin EBA’daki içerikleri dikkat çekici, güdüleyici ve eğlenceli buldukları ve görselliğin kalıcılığı arttırmada etkisinin olduğunu dile getirdikleri belirlenmiştir. Benzer şekilde sınıf öğretmenleri ile yapılan başka bir çalışmada EBA'nın yararları araştırılmıştır. Sınıf öğretmenleri EBA’nın yararlarını, öğrenme sürecine görsellik kattığı ve bilgiye kolay ulaşma imkânı sağladığı şeklinde sıralamışlardır (Kurtdede, Erbasan ve Kolsuz, 2016). Alan yazındaki benzer çalışmalara bakıldığında teknolojinin eğitime entegrasyonunun öğrenci akademik başarısına olumlu etkisi olduğuna dair bulgulara rastlanmıştır (Karaman, Yıldırım ve Kaban, 2008; Öğreten ve Uluçınar-Sağır, 2013). Bir başka 
çalışmada web destekli EBA videolarının zengin içeriğinden ötürü öğrencileri motive etmede olumlu etkilere sahip olduğu belirlenmiştir (Aydınözü, Sözcü ve Akbaş 2016). Bu kapsamda bu araştırmanın sonuçları alan yazındaki diğer araştırma sonuçları ile benzerlik göstermektedir. Diğer taraftan İnam ve Ünsal (2017), beşinci sınıflar ile yaptıkları çalışmada web destekli öğretimin özellikle matematik derslerinde öğrencilerin konu odaklı motivasyonları üzerinde olumlu bir etkisinin olmadığı sonucuna ulaşmışlardır. Bu bulgu, bu çalışmada elde edilen sonuçlar ile farklılaşmaktadır.

Araştırmada elde edilen sonuçlar EBA video modüllerinin Fen Bilimleri dersinde kullanılmasının, Fen Bilimleri başarısına ve Fen Bilimleri dersine olan motivasyonu arttırmada etkili olabileceğini ortaya koymaktadır. EBA kullanılarak işlenen dersin daha zevkli geçtiği ifade edilebilir. Önemli olan bir diğer sonuç ise, öğrencilerin EBA video modüllerinin okulda kullanımı sırasında aksaklıklar yaşandığını belirterek okulda kullanıma uygun olmadığını ancak evde kendi bireysel çalışma hızları doğrultusunda videolardan faydalanmalarının daha verimli olacağını ifade etmiş olmalarıdır. Bu çalışmanın sonuçlarına bağlı olarak aşağıdaki öneriler sunulabilir.

Bu çalışma Fen Bilimleri dersi için EBA video kullanımına ilişkin öğrenci görüşlerini içermektedir. Diğer derslerde benzer çalışmaların yapılmasının EBA platformunun daha işlevsel hale getirilebilmesi için önemli olduğu düşünülmektedir.

$\mathrm{Bu}$ çalışma sekizinci sınıf öğrencileri ile yürütülmüştür. Bundan sonraki yapılacak çalışmaların farklı öğretim kademesinde öğrenim gören öğrenciler ile yürütülerek, EBA video modüllerinin Fen Bilimleri dersinde kullanımını daha net görülebilir.

Bu çalışmada ve daha önce yapılan çalışmalardan, EBA'daki videoların içeriklerinin zayıf olduğu sonucuna ulaşılmıştır. Bundan dolayı EBA'daki Fen Bilimleri dersi video içeriklerinin zenginleştirilmesi önerilmektedir.

\section{Makalenin Bilimdeki Konumu}

Matematik ve Fen Bilimleri Eğitimi Bölümü/Fen Bilgisi Eğitimi

\section{Makalenin Bilimdeki Özgünlüğü}

Yaklaşık olarak bir buçuk yıldır Dünya üzerinde etkili olan Covid-19 salgını, ülkeleri birçok alanda etkisi altına almıştır. Bu alanlardan etkilenen kurumların başından eğitim-öğretim kurumları gelmektedir. Salgının etkisi altında kalan bütün ülkelerde olduğu gibi ülkemizde de eğitim-öğretim uzaktan eğitim yoluyla verilmeye başlanmıştır. Uzaktan eğitimin önemli bileşenlerinden birisi de EBA'dır. $\mathrm{Bu}$ ağ vasıtasıyla Türkiye'de uzaktan eğitim gerçekleştirilmektedir. EBA ile en çok etkileşim halinde olanların öğretmenler, öğrenciler ve 
veliler olduğu söylenebilir. Öğrencilerin Fen Bilimleri dersinde kullanılan videoların kendi öğrenmelerinde ne kadar etkili olup olmadığının ortaya koyulması adına bu çalışmanın önemli olduğu düşünülmektedir. Bunun yanı sıra EBA'da kullanılan ders videolarının fayda ve eksikliklerinin ortaya çıkarılması, EBA'nın öğrenme ortamında etkililiğinin artırılması açısından bu çalışma önem arz etmektedir.

\section{Kaynaklar}

Açıkgöz, G. (2018). Ĕğitim bilişim ă̆ destekli matematik öğretiminin 7. sınıf öğrencilerinin akademik başarısına etkisi. Yayımlanmamış doktora tezi, Kastamonu Üniversitesi, Kastamonu.

Akdeniz, A. R. Öztürk, M. ve Bakırcı H. (2017). Bilgisayar destekli öğretim uygulamalarının sekizinci sınıf öğrencilerinin fen dersi akademik başarılarına ve bilginin kalıcılığına etkisi. Hasan Ali Yücel Ĕgitim Fakültesi Dergisi, 14(2), 59-77.

Akıncı, A., Kurtoğlu, M. ve Seferoğlu, S. S. (2012). Bir teknoloji politikası olarak FATíH projesinin başarılı olması için yapılması gerekenler: Bir durum analizi çalışması. Akademik Bilişim, 3(1), 1-10.

Aktay, S. ve Keskin, T. (2016). Eğitim bilişim ağı incelemesi. Eğitim Kuram ve Uygulama Araştırmaları Dergisi, 2(3), 27-44.

Alabay, A. (2015). Ortaöğretim öğretmenlerinin ve ögrencilerinin eğitimde bilişim ă̆l kullanımına ilişkin görüşleri üzerine bir araştırma. Yayımlanmamış yüksek lisans tezi, İstanbul Aydın Üniversitesi, İstanbul.

Alabay, A. ve Taşdelen, V. (2017). Ortaöğretim öğretmenlerinin ve öğrencilerinin eğitimde bilişim ağı kullanımına ilişkin görüşleri üzerine bir araştırma. İstanbul Aydın Üniversitesi Eğitim Fakültesi Dergisi, Özel Sayl, 27-29.

Alaca, E. ve Yılmaz, B. (2016). Bilgi ve iletişim teknolojilerinin kullanımı ve bilgi toplumuna dönüşüm: Türkiye'de durum. Türk Kütüphaneciliği, 30(3), 507-523.

Altın, H. M. ve Kalelioğlu, F. (2015). FATİH projesi ile ilgili öğrenci ve öğretmen görüşleri. Başkent University Journal of Education, 2(1), 89-105.

Ar, K. Z. (2016). Ortaöğretim öğretmenlerinin derslerinde bilişim teknolojilerini kullanma ile ilgili görüşleri. Yayımlanmamış yüksek lisans tezi, Sakarya Üniversitesi, Sakarya.

Atasoy, M. ve Yiğitcan-Nayir, Ö. (2019). Eğitim bilişim ağı video modüllerinin matematik dersinde kullanımına ilişkin öğrenci görüşleri. Uluslararası Bilim ve Ĕgitim Dergisi, 2(1), 24-37. 
Ateş, M., Çerçi, A. ve Derman, S. (2015). Eğitim bilişim ağında yer alan Türkçe dersi videoları üzerine bir inceleme. Sakarya University Journal of Education, 5(3), 105-117.

Aydınözü, D. Sözcü, U. ve Akbaş, V. (2016). Coğrafya öğretiminde eğitim bilişim ağı içeriklerinin öğrenci başarısına etkisi. Karadeniz Sosyal Bilimler Dergisi, 8(15), 343-361.

Bahceci, F. ve Efe, B. (2018). Lise öğrencilerinin eğitim bilişim ağ1 sitesine yönelik görüşlerinin değerlendirilmesi. Kuramsal Ĕ̆itimbilim Dergisi, 11(4), 676-692.

Bektaş, M. (2019). Ortaöğretim öğrencilerinin mobil uygulamaları eğitsel amaçlı kullanma durumlarının incelenmesi: Sakarya Kaynarca örneği. Yayımlanmamış yüksek lisans tezi, Sakarya üniversitesi, Sakarya.

Brown, J. L. (2012). Online learning: A comparison of web-based and land-based courses. Quarterly Review of Distance Education, 13(1), 39-42.

Çakmak, Z. ve Taşkıran, C. (2017). Sosyal bilgiler öğretmenlerinin perspektifinden eğitim bilişim ağı platformu. Uluslararası Türk Eğitim Bilimleri Dergisi, 9, 284-295.

Denzin, N. K. \& Lincoln, Y. S. (1994). Handbook of qualitative research. Sage Publications, California, USA.

Efe, H. A., Oral B., Efe R. ve Sünkür, M. Ö. (2011). The effects of teaching photosynthesis unit with computer simulation supported co-operative learning on retention and student attitude to biology. Necatibey Eğitim Fakültesi Elektronik Fen ve Matematik Eğitimi Dergisi, 5(1), 313-329.

Gezer, M. ve Durdu, L. (2020). Eğitim bilişim ağı ile ilgili tezlerin sistematik analizi. Başkent University Journal of Education, 7(2), 393-408.

Güvendi, M. G. (2014). Millî Eğitim Bakanlı̆̆ı'nın öğretmenlere sunmuş olduğu kullanım eğitim ve paylaşım sitelerinin öğretmenlerce sıllı̆̆l: Ĕ̆itim bilişim ă̆g örneği. Yayımlanmamış yüksek lisans tezi, Sakarya Üniversitesi, Sakarya.

İnam, A. ve Unsal, H. (2017). Ortaokul 5. sınıf matematik uygulamaları dersinin web destekli öğretiminin öğrenci performans ve motivasyonuna etkisi ile öğrenci görüşlerinin değerlendirilmesi. HAYEF: Journal of Education, 14(1), 203-222.

Kana, F. ve Saygıl1, D. (2016). Ortaöğretim Türk dili ve edebiyatı dersinde eğitim bilişim ağının kullanımına yönelik öğrenci görüşlerine yönelik bir durum çalışması. Akdeniz Eğitim Araştırmaları Dergisi, 20, 11- 23.

Karaman, S., Yıldırım, S. ve Kaban, A. (2008). Öğrenme 2.0 yaygınlaşıyor: Web 2.0 uygulamalarının eğitimde kullanımına ilişkin araştırmalar ve sonuçları. XIII. Türkiye’de Internet Konferansı Bildirileri, Orta Doğu Teknik Üniversitesi, Ankara. 
YYÜ Eğitim Fakültesi Dergisi (YYU Journal of Education Faculty), 2021; 18(1)685-705,http://efdergi.yyu.edu.tr.

Kırıcı, M. G., Artun, H. ve Bakırcı, H. (2018). Eğitim bilişim ağı destekli eğitimin kuvvetin ölçülmesi ve sürtünme kavramlarının öğrenilmesine etkisi. Turkish Studies, 13(6), 23-38.

Kurtdede-Fidan, N., Erbasan, Ö. ve Kolsuz, S. (2016). Sınıf öğretmenlerinin eğitim bilişim ağından yararlanmaya iliş̧in görüşleri. Uluslararası Sosyal Araştırmalar Dergisi, 9(45), 626-637.

Lee, M. \& Baylor, A. L (2006). Designing metacognitive maps for web-based learning. Educational Technology \& Society, 9(1), 344-348.

McMillan, J. H. \& Schumacher, S. (2014). Research in education: Evidence-based inquiry. Harlow, UK.

Merriam, S. B. (2013). Nitel araştırma desen ve uygulama için bir rehber (Çeviren: S. Turan) Ankara: Nobel Yayıncılık.

Miles, M. B. \& Huberman, A. M. (1994). Qualitative data analysis: An expanded sourcebook. Sage.

Milli Eğitim Bakanlığı (2015). Eğitimde FATİH projesi web sayfası erişim. http.meb.gov. tr/index. php. Adresinde 01. 01. 2021 tarihinde ulaşılmıştır.

Namlu, A. G. (1999). Teknoloji öğrenmede ne kadar etkili. Anadolu Üniversitesi Eğitim Fakültesi Dergisi, 9, 1-2.

Öğreten, B. ve Uluçınar-Sağır, Ş. U. (2013). 4. sınıf fen ve teknoloji dersinde interaktif öğretimin akademik başarıya ve tutuma etkisi. Batı Anadolu Eğitim Bilimleri Dergisi, 4(7), 1-18.

Özbay, M. (2008). Türkçe özel öğretim yöntemleri I. Ankara: Öncü Yayıncılık.

Özkan, H. (2019). Etkileşimli tahtanın öğretimde kullanımının değerlendirilmesi. Yayımlanmamış yüksek lisans tezi, Balıkesir Üniversitesi, Balıkesir.

Saklan, H. ve Ünal, C. (2018). Teknoloji dostu fen bilimleri öğretmenlerinin eğitim bilişim ağ1 hakkındaki görüşleri. Necatibey Eğitim Fakültesi Elektronik Fen ve Matematik Eğitimi Dergisi, 12(1), 493-526.

Türkiye İstatistik Kurumu. (2020). https://www.aa.com.tr/tr/bilim-teknoloji/turkiyede-internetkullanim-orani-yuzde-79-oldu/1952297. Adresinde 10.01. 2021 tarihinde ulaşılmıştır.

Tüysüz, C. ve Çümen, V. (2016). Eğitim Bilişim Ağı ders web sitesine ilişkin ortaokul öğrencilerinin görüşleri. Uşak Üniversitesi Sosyal Bilimler Dergisi, 9(27/3), 278-296.

Woodside, A. (2010). Case study research: Theory, methods, practice. Bingley: Emerald Group Publishing Limited. 
YYÜ Eğitim Fakültesi Dergisi (YYU Journal of Education Faculty), 2021; 18(1)685-705,http://efdergi.yyu.edu.tr, doi:10.33711/ yyuefd.919600

Yavuz, S. ve Coşkun, E. A. (2008). Sınıf öğretmenliği öğrencilerinin eğitimde teknoloji kullanımına ilişkin tutum ve düşünceleri. Hacettepe Üniversitesi Eğitim Fakültesi Dergisi, 34(34), 276-286.

Yıldırım, A. ve Şimşek, H. (2011). Sosyal bilimlerde nitel araştırma yöntemleri. Ankara: Seçkin Yayıncılık. 


\section{Summary}

\section{Statement of Problem}

Education Information Network (EIN) is a website designed for the use of students and teachers (Atasoy \& Yiğitcan-Nayir, 2019). Therefore, revealing the positive and negative aspects of EIN will help to understand how the programme can be developed (Bahçeci \& Efe, 2018). In order to overcome the deficiencies in EIN, it is important to continue working with teachers and students who constantly interact with the site. The literature shows that EIN video modules are used within the scope of the Science course (Kırıc1, Artun \& Bakırc1, 2018). The research argues that the use of videos developed academic skills and technological interests of the students. However, research focussing on student views of video modules in EIN are limited. On the other hand, exploring students' opinions about video modules will contribute to further research. In addition, this study is important for eighth grade students who have been using EIN actively due to the pandemic, and therefore they will be in a better position to express shortcomings about EIN. In the light of this information, the main problem of the study was determined as "What are the opinions of eighth grade students regarding the use of video modules related to the Science course in Education Information Network (EIN)?" The following questions were responded within the scope of this research problem;

1. What are the advantages of using EIN videos in science class?

2. What are the missing parts in the science class that is taught without using EIN videos?

3. What are students' difficulties in the science class that is taught using EIN videos?

4. What is the opinion of students about sufficiency of EIN video content for the Science course?

5. What are the most striking aspects of EIN videos that motivate students?

\section{Method}

The research is informed by qualitative research design and employs case study. The participants of the research are 10 eight grade secondary school students studying in Tusba in Van during 2020-2021 academic year. Convenient sampling was used to recruit the participants. Seven of the students were female and three were male. Semi-structured interviews were conducted to collect data. These interviews enable the participants to express themselves easily and to obtain in-depth information (Yıldırım \& Şimşek, 2011). Descriptive and content analysis was used to analyse the data. The purpose of using descriptive and content analysis is to present 
the data by simplifying and interpreting it in a way that readers can understand. The students participating in the interview were coded as S1, S2, S3... S10.

\section{Findings}

Table 1 shows that students have different opinions about the advantages of EIN video modules. For instance S3 says "The visuality is better, the subjects are clearer, I can revise the topics I don't understand." The use of EBA video modules in the Science course is effective in understanding the subject and the videos are enriched with visuals. Students 5 notes: "Using EIN videos give us an advantage. The activities reinforce the topics so we are not bored while studying. Therefore, it helps us to be more successful in Science." He added that EIN video modules contain effective contents to increase academic success. The themes and codes obtained from the responses are presented in Table 2.

When Table 2 is examined, the participants expressed their views under the theme of "Limitations of the lessons taught without using EIN videos" and said that visuality is used less in the course and it is not always possible to experiment, and they have difficulty understanding the subject. In this regard, S3 stated that; "If I cannot fully understand the topics, I cannot solve questions and I am wasting time. When we do not have videos or visuals, it is difficult to understand the topics”. It was stated that the videos contributed to the students' meaningful learning in the Science course. In addition, S3 emphasized that, "At school, I understand the course much better, but we cannot always do experiments. In videos, when the teacher displays the videos, I do understand it better." Thus, the student highlighted that teachers create an experiment environment in videos an create a more real-life experience'

\section{Conclusion and Discussion}

The students expressed the following advantages of EBA videos in science teaching; addressing more than one sense, providing easy understanding of the subjects, offering the opportunity to learn at any time and revising the subjects. Courses that use EIN videos help students understand the subject both visually and audibly. Research on technology-supported science teaching show that technological tools such as video, computer and simulation were effective on students' academic achievement and scientific thinking skills in science classes (Akdeniz, Öztürk \& Bakırcı, 2017). Similarly, Açıkgöz (2018) concluded that EIN-supported mathematics teaching reinforces the topics, provides the opportunity to repeat the topics, improves test solving skills and increases academic success. Likewise, Tüysüz and Çümen 
(2016) conducted a study on secondary school students, and they found that EIN increases academic success, provides the opportunity to take tests and repeat topics. The results of this study show that they are similar to the results of other studies in the literature (Alabay, 2015; Atasoy \& Yiğitcan-Nayir, 2019; Gezer \& Durdu, 202). The students stated that EIN video supported science teaching makes learning fun. This is because students perceive the teaching different than the course book. Moreover, videos encourage game-based thinking and they spend time with tablets, phones or computers throughout the day.

The students drew attention to many aspects of the science course, which is taught without using EIN videos. Some of the disadvantages were listed as having visual deficiencies, insufficient opportunity to make experiments, and lecturing based on memorization. Lack of equipment in schools, intensity of the curriculum, and affordability are also other potential problems students face. The studies on EIN emphasize that effective use of materials by teacher depends on physical infrastructure (Saklan \& Cezmi, 2018). Similarly, Alabay (2015) stated that the reason for not active use of EIN platform by teacher is based on lack of infrastructure in schools. The students stated that opportunity to have experiment is not always there. It is considered that this finding is related with the dangers to be encountered during the experiment in the Science course, the crowded classroom environment, inappropriate material, and physical environments. Technology becomes more important in classrooms where experiments are not conducted and where there are adverse conditions. The study conducted in this context by Efe, Oral and Efe Sünkür (2011) stated that the use of simulation is more effective in improving students' cognitive skills. Students are more interested in classes where technology is used functionally (Saklan \& Cezmi, 2018). Therefore, using EIN videos in the Science course will make the course more visual. It will also provide the opportunity to teach more efficiently with simulation teaching when they do not have the opportunity to experiment due to lack of facilities.

\section{Ek-1: Yarı Yapılandırılmış Görüşme Formu}

1. Fen bilimleri dersinde EBA videoları kullanmanın avantajları nelerdir?

2. EBA videoları kullanılmadan işlenen fen dersinde eksik gördüğün yerler nelerdir?

3. EBA Videoları Kullanılarak İşlenen Fen Bilimleri Dersinde Zorlandığın Kısım Nelerdir?

4. Sekizinci sınıf öğrencilerinin EBA video içeriklerinin Fen Bilimleri dersi için yeterli olup olmadığı konusundaki düşüncelerin nelerdir?

5. EBA videolarında en çok dikkatinizi çeken sizi güdüleyen yönler nelerdir? 